\section{A WINTER MISCELLANY OF CYCLING, SPORT, SOCIAL CAPITAL, AND EPIDEMIOLOGY}

A varied issue this month, with contributions ranging from the theoretical concerning the role of carcinogenesis in evolution and a new consideration of the concept of causation, to the challenge of evaluation of a mega environmental public health intervention in the form of a national cycle network in the United Kingdom.

See pages $86,89,96$

Our Speaker's corner highlights the Argentinean paradox of inequalities in child health, with both diseases of affluence and poverty coexisting. The $\mathrm{JECH}$ celebrates a major protest against privatisation of the social security system in El Salvador.

See pages 82,83

\section{www.jech.com}

Awareness of the public health issues surrounding large scale public events has been heightened in the aftermath of the September 11 atrocity in New York in 2001, and there is increased recognition of the need to share experience of good practice. The public health surveillance system established for the Sydney 2000 Olympic Games is one such example which is reported here.

See page 102

The shift of emphasis in healthcare systems towards primary care requires a much better evidence base, and a report from England on previous consultation on self reported health status as predictors of future demand for primary care looks like a fruitful vein of inquiry.

\section{See page 109}

The growth of interest in social capital is reflected in a contribution exploring its relation with middle aged female and male mortality rates in Hungary, and although this may be no surprise to many the importance of the finding that limiting access to firearms is a potentially effective means of reducing suicide mortality cannot be stated often enough and clearly (this from the USA!).

See pages 114, 120

A set of Research Reports include further evidence on income related inequalities in self assessed health; the relation between body mass index and mortality in an unusually slim cohort; and geographical variation in the epidemiology of cardiovascular disease in older women. We also carry findings on the associations of height, leg length, and lung function with cardiovascular risk factors; job strain, job demands, decision latitude and risk of coronary heart disease (in Whitehall); and the effect of work related variables on growth among working boys (10 to 16 year olds in Jordan) - the length of time these children work seems to have a detrimental effect on growth.

See pages 125, 130, 134, 141, 147, 154

Finally, two letters on tobacco control. Most encouragingly and important for action, strong evidence that no smoking policies in the hospitality trade are popular with customers and are much more likely to increase rather than decrease trade.

See page 159 